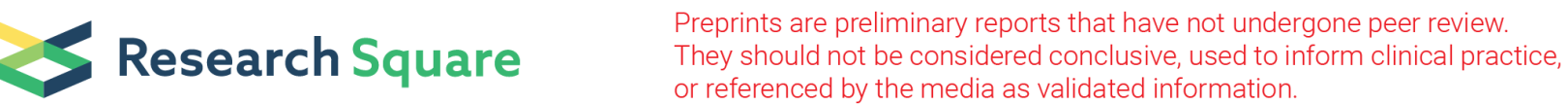

\section{Comparison of the efficacy and safety between palliative biliary stent placement and duct clearance among elderly patients with choledocholithiasis: A propensity score-matched analysis}

Koh Kitagawa ( $\sim$ kitagawa@naramed-u.ac.jp )

Nara Medical University

Akira Mitoro

Nara Medical University

Takahiro Ozutsumi

Nara Medical University

Masanori Furukawa

Nara Medical University

Yukihisa Fujinaga

Nara Medical University

Norihisa Nishimura

Nara Medical University

Yasuhiko Sawada

Nara Medical University

Tadashi Namisaki

Nara Medical University

Takemi Akahane

Nara Medical University

Hitoshi Yoshiji

Nara Medical University

\section{Research Article}

Keywords: aged, choledocholithiasis, endoscopic retrograde cholangiopancreatography, lithotripsy, stents

Posted Date: August 24th, 2021

DOl: https://doi.org/10.21203/rs.3.rs-827344/v1

License: (c) (i) This work is licensed under a Creative Commons Attribution 4.0 International License.

Read Full License 
Page $2 / 18$ 


\section{Abstract \\ Objectives}

This study aimed to evaluate and compare the outcomes of palliative endoscopic biliary stenting (EBS) and complete stone removal among elderly patients with choledocholithiasis using propensity score matching.

\section{Methods}

From April 2012 to October 2017, 161 patients aged 75 years and older with choledocholithiasis underwent endoscopic retrograde cholangiopancreatography at our institution. Among them, 136 (84.5\%) had complete stone removal, and 25 (15.5\%) underwent palliative EBS without further intervention until symptom occurrence. The median age of the EBS group was significantly higher than that of the complete stone removal group. The proportion of patients with dementia, cerebral infarction, preserved gallbladder with gallstones, and surgically altered anatomy was higher in the EBS group than in the complete stone removal group. Propensity score matching was used to adjust for different factors. In total, 50 matched patients ( $n=25$ in each group) were analyzed.

\section{Results}

The median duration of cholangitis-free periods was significantly shorter in the EBS group (596 days) than in the complete stone removal group. About half of patients in the EBS group required re-treatment and re-hospitalization for cholangitis during the observation period. Cholangitis was mainly caused by stent migration. There was no significant difference in terms of mortality rate and procedure-related adverse events between the two groups. Death was commonly attributed to underlying diseases. However, one patient in the EBS group died due to severe cholangitis.

\section{Conclusions}

Palliative EBS should be indicated only to patients with choledocholithiasis who have a poor prognosis.

\section{Introduction}

Choledocholithiasis commonly occurs during the migration of gallstones from the gallbladder to the biliary tree. Gallstones are caused by the lower contractility of the biliary epithelium due to multiple factors including supersaturation of cholesterol in the bile, inadequate bile salt concentration and function, diet, hormone levels, and genetic predisposition.[1, 2] Furthermore, the incidence of choledocholithiasis increases with age.[3] Minimally invasive endoscopic procedures play an important role in the treatment of choledocholithiasis. Stone removal via endoscopic retrograde 
cholangiopancreatography (ERCP) is the first choice for the management of choledocholithiasis in recent years.[4] However, in some cases, complete stone removal can be challenging to perform due to patient characteristics such as age and underlying diseases, surgically altered anatomy, and stone factors including size and number.[5] Further, additional surgical cholecystectomy cannot be performed in elderly patients with poor general conditions who have undergone complete stone removal from the bile duct via ERCP. Thus, stone recurrence may occur.[6-8] In recent years, due to the aging population, palliative endoscopic biliary stenting (EBS) is sometimes the treatment of choice for high-risk elderly patients. EBS alone is associated with good survival among elderly patients who have not undergone complete stone removal.[9-11] Furthermore, some studies have shown that EBS can reduce the number and size of stones and facilitate stone removal for a period of time.[12-15] However, it is associated with stentrelated complications such as stent occlusion and migration, and the American Society of Gastrointestinal Endoscopy (ASGE) guidelines state that management should aim at periodic stent replacement and eventual stent removal, without recommendations for permanent EBS.[4] Moreover, the efficacy of palliative EBS among frail elderly patients with choledocholithiasis remains controversial.

Large, high-quality studies conducted in the 1990s have reported the outcomes of palliative EBS.[16, 17] About 30 years since then, the aging society has become more advanced. Further, treatment techniques for "difficult stones" are rapidly improving, and multiple large stones and surgically altered anatomy can now be managed endoscopically. Therefore, the efficacy of palliative EBS and duct clearance should be assessed and compared again at the present time. Hence, this study aimed to retrospectively evaluate and compare the outcomes of palliative EBS and complete stone removal among elderly patients with choledocholithiasis using propensity score matching (PSM).

\section{Methods}

\section{Study population}

This study was approved by the institutional review board of Nara Medical University Ethics Committee (\#1360). Figure 1 shows the patient flow chart in this study. From April 2012 to October 2017, 278 patients with total choledocholithiasis underwent ERCP at our institution. Among them, 109 who were aged younger than 75 years and 8 who had an unsuccessful ERCP were excluded from the study. Meanwhile, the remaining 161 patients were included in the analysis. In total, 136 (84.5\%) patients had complete stone removal, and 25 (15.5\%) underwent palliative EBS without further intervention until symptom occurrence. The physician performed either complete stone removal or palliative EBS based on the patient's condition and stone status. The EBS group also included cases in which stone removal was initially attempted but was difficult, and thereby palliative stenting was unavoidable with the stone remaining. None of the patients had routine or planned stent replacement. Information regarding patient characteristics and endoscopic procedures was obtained from the medical records. All authors had access to the study data and approved the final manuscript. This study was performed according to the Strengthening the Reporting of Observational Studies in Epidemiology (STROBE) Statement. The 
requirement for written informed consent to participate in the study was replaced by an opt-out method, owing to the retrospective nature of this study.

\section{ERCP}

Patients were placed in prone position and were sedated with midazolam and buprenorphine hydrochloride, or haloperidol as appropriate. Vital signs were monitored with electrocardiogram and oxygen saturation assessment during ERCP. Patients received oxygen therapy via nasal cannula if needed. ERCP was performed using standard duodenoscopes (TJF260V and JF260V; Olympus Medical, Tokyo, Japan). Moreover, a balloon-assisted endoscope (EC-450BL5; Fujifilm Medical, Tokyo, Japan) was utilized in patients with surgically altered anatomy (except for Billroth I method). Selective bile duct cannulation was performed with wire-guided cannulation and contrast medium injection methods using a standard ERCP catheter (MTW ERCP catheter; Medi-Globe GmbH, Rohrdorf, Germany) or a sphincterotome (CleverCut 3V; Olympus Medical, Tokyo, Japan). EBS was performed using straight or pig tail plastic stents. In patients who underwent endoscopic papillary balloon dilation (EPBD), a 6- to 10-mm balloon catheter (HurricaneTM RX; Boston Scientific Japan, Tokyo, Japan) was used for balloon dilation. Endoscopic large balloon dilation (EPLBD) was performed using a 12- to 20-mm balloon catheter (CRE wire-guided balloon dilator; Boston Scientific Japan, Tokyo, Japan). In this study, none of the patients received rectal indomethacin during the periprocedural period.

\section{PSM}

Table 1 shows the characteristics of patients. The EBS group had a significantly higher proportion of elderly individuals and those with dementia, history of brain stroke, preserved gallbladder with gallstones, surgically altered anatomy, periampullary diverticulum, and large bile duct and stones. However, there was no significant difference in stone number between the EBS and complete stone removal groups.

PSM was performed to control for factors affecting the choice between complete stone removal and bile duct stenting. Two groups were matched using a 1:1 ratio (stone removal, $n=25$; palliative EBS, $n=25$ ) via a propensity score-matched analysis adjusted for fourteen covariates to minimize inherent bias. Each patient in the EBS group was matched to a patient in the stone removal group using the nearest-neighbor method with a caliper range of 0.20 of the standard deviation of the pooled propensity scores. All patient factors were eventually matched, and there was no significant difference between the two groups.

\section{Statistical analysis}

Categorical variables were compared using the chi-square test or the Fisher's exact test, and continuous variables using the $t$-test or the Mann-Whitney $U$ test. A p value of $<0.05$ was considered statistically significant. The duration of cholangitis-free periods was assessed using the Kaplan-Meier method and was compared between the two groups with the log-rank test. The duration of cholangitis- and death-free periods was censored at the end of each patient's follow-up period. All statistical analyses were performed using EZR (version 1.41; Saitama Medical Center, Jichi Medical University, Saitama, Japan; 
http://www.jichi.ac.jp/saitama-sct/ SaitamaHP.files/statmedEN.html), which is a graphical user interface for R (The R Foundation for Statistical Computing, Vienna, Austria, version 4.0.3).[18]

\section{Endpoints and definitions}

The primary endpoint of our study was the time to recurrence of cholangitis after complete stone removal and palliative EBS among elderly patients with choledocholithiasis. The secondary endpoints were causes and severity of cholangitis, incidence of adverse events (AEs), mortality rate, and causes of death. If cholangitis developed after ERCP, its diagnosis and severity were defined according to the Tokyo Guideline 2018.[19] Early AEs were defined as AEs occurring within 14 days, and late AEs as AEs occurring after 14 days after the procedure. AE severity was graded according to the ASGE lexicon.[20]

\section{Results}

\section{Endoscopic procedure and AEs}

Table 2 depicts the endoscopic procedures. Three (12.0\%) patients in the EBS group received ampullary interventions. These three patients had initially undergone ampullary interventions in an attempt to remove the stone completely, but it was difficult and the procedure was changed to palliative stenting with the stone remaining. Meanwhile, all patients in the stone removal group, including 18 (72.0\%), 1 (4.0\%), and 6 (24.0\%) who underwent endoscopic sphincterotomy (ES), EPBD alone, and EPLBD with ES, respectively, had ampullary interventions. In the EBS group, straight type plastic and pig tail type stents were used in $68.0 \%$ and $32.0 \%$ of patients, respectively. The most common stents used were $7 \mathrm{~cm}$ in length and $7 F$ in diameter. The number of ERCP sessions was slightly higher in the stone removal group than in the EBS group. Table 2 shows data about AEs other than cholangitis. In the EBS group, early AEs included acute pancreatitis $(n=1)$, aspiration pneumonia $(n=1)$, and retroperitoneal perforation $(n=1)$. In addition, one patient presented with acute cholecystitis, which is considered a late AE. Two patients in the stone removal group had acute pancreatitis. The incidence of AEs did not significantly differ between the EBS and complete stone removal groups $(16.0 \%$ and $8.0 \%, p=0.67)$. There were no procedure-related deaths in both groups.

\section{Duration of cholangitis-free periods}

The Kaplan-Meier curve for cholangitis-free duration is shown in Figure 2. The median cholangitis-free period in the EBS group was 596 days (95\% confidence interval, 187-1240 days); however, the median cholangitis-free period in the stone removal group could not be estimated during the observation period. The stone removal group had significantly longer cholangitis-free period than the EBS group (Log-Rank test; $p<0.01$ ). Table 3 shows the incidence, cause, and severity of cholangitis. About half of patients in the EBS group developed cholangitis, and it was significantly more common in the EBS group than in the stone removal group $(p<0.01)$. Stent migration was the most common cause of cholangitis in the EBS group. Furthermore, one patient in the EBS group had stent-stone complex. Thus, the old stent was difficult to remove (Figure 3). By contrast, only one patient in the complete stone removal group presented 
with cholangitis, which was caused by recurrence of bile duct stones. All patients with cholangitis were treated again with ERCP, and all reinterventions were technically successful. Most patients presented with moderate cholangitis. However, one patient in the EBS group died due to severe cholangitis.

\section{Mortality}

During a median observation period of 442.5 (range: 8-2364) days, $3(12.0 \%)$ patients in the EBS group and $2(8.0 \%)$ in the complete stone removal group died. There was no significant difference in terms of mortality rate between the two groups. Death was commonly caused by underlying diseases. However, one patient in the EBS group died due to severe cholangitis. The length of hospital stay was also examined, and the result did not significantly differ between the two groups (Table 3).

\section{Discussion}

Endoscopic lithotripsy is the first choice for the treatment of choledocholithiasis. Minimally invasive endoscopic treatment, which is safe even among frail elderly patients with underlying diseases, has been increasingly used. However, in actual clinical practice, patients may not endure long procedures. Thus, the procedure can be discontinued, thereby leaving a biliary stent alone. Bergman et al. assessed the outcomes of long-term treatment with $10-\mathrm{F}$ polyethylene stents among elderly patients $(n=58)$.[16] This method was initially successful. However, over time, $38 \%$ of patients developed recurrent cholangitis, and in $12 \%$ of cases, it was fatal. Chopra et al. found that ductal clearance was consistently associated with a higher rate of procedural AEs in a randomized comparison between ductal clearance and long-term biliary stenting (16\% vs. $7 \%$ ). However, the incidence of long-term biliary AEs was lower (14\% vs. 36\%).[17] By contrast, there are some reports showing that long-term stenting is beneficial for high-risk elderly patients with choledocholithiasis.[9-11] However, the validity of long-term EBS remains controversial.

In retrospective studies comparing complete stone removal and long-term EBS, selection bias is more likely to occur because a high number of elderly patients and those with poor general health are included in the EBS group. In this study, this bias was eliminated by including only patients aged 75 years and older in the target population and by matching patient factors between the two groups via PSM.

Interestingly, when we compared the background characteristics of patients before PSM in our study, we found significant differences in terms of patient factors (such as age and underlying diseases) and anatomical factors (including periampullary diverticulum and surgically altered anatomy). However, there was no significant difference in terms of the number of stones. Furthermore, the patients in the EBS group were more likely to have larger stones. Nevertheless, the median diameter was only $10 \mathrm{~mm}$. In recent years, the technique used to remove the so-called difficult stones has significantly improved. New ampullary interventions including EPLBD were found to be useful in the treatment of large and multiple stones.[21-23] Moreover, lithotripsy techniques including electronic hydraulic lithotripsy using a digitalsingle-operator cholangioscopy have also been developed.[24, 25] This suggests that the general condition of the patients rather than stone factors may affect the choice of palliative EBS in our study. In addition, before PSM, the EBS group was likely to have a surgically altered anatomy. In recent years, 
ERCP with a balloon-assisted endoscope was found to be effective in patients with surgically altered anatomy.[26-28] However, the technique is still challenging, and the procedure was longer in such cases. This might increase the number of cases in which the stones were not completely removed even after a successful ERCP and the procedure was discontinued with stenting alone.

In the current study, the incidence of $A E$ and mortality rate did not significantly differ. However, the median time to cholangitis was significantly shorter in the EBS group than in the complete stone removal group. There was no significant difference between the two groups in terms of treatment safety or length of hospital stay. Nevertheless, about half of the patients in the EBS group eventually required reintervention and re-hospitalization. More importantly, one patient in the EBS group died due to severe cholangitis. In the EBS group, the main cause of stent dysfunction was stent migration, which might have been caused by the fact that the stent was placed in the bile duct without stenosis. Additionally, in our study, there was a case of stent-stone complex in the EBS group. Kaneko et al. showed that long-term EBS increases the risk of stent-stone complex.[29] Stent-stone complex formation can lead to difficulties in removing old stents via conventional endoscopic procedures.

By contrast, the median duration of cholangitis-free periods in patients with palliative EBS was 596 days. Therefore, palliative EBS may be acceptable in patients with malignancies who have a poor prognosis. However, the indications should be limited. Even in cases in which biliary stenting was unavoidable at the time of initial treatment, it may be necessary to perform the procedure again after the patient's general condition improves to achieve complete stone removal or to consider planned stent replacement.[30]

In addition, in some elderly patients with choledocholithiasis, even if the bile duct stones are removed via ERCP, the gallbladder stones may not be surgically resected thereafter. In our study, even in the matched cohort adjusted for the proportion of patients with residual gallbladder with gallstones after ERCP, the incidence of cholangitis was significantly lower in the stone removal group. Yasui et al. showed that the recurrence of choledocholithiasis did not increase even if the gallbladder with gallstones is preserved after endoscopic treatment of choledocholithiasis among elderly patients.[31] Therefore, regardless of whether cholecystectomy is feasible in the future, a reasonable therapeutic strategy should be used to completely remove bile duct stones.

The current study had several limitations. First, patients with inadequate follow-up were included. This study included a high number of elderly patients with underlying medical conditions. In some cases, regular outpatient visits were challenging. Therefore, long-term prognosis could not be assessed, and some patients were censored using the Kaplan-Meier curve. Second, this is a retrospective study, which may not be as statistically reliable as randomized control trials. However, in this study, the background characteristics of the stone removal group and the EBS group were adjusted using PSM to ensure homogeneity between the two groups. We believe that the statistical reliability of this study is sufficient. Third, because the outcome of the study was the occurrence of cholangitis, the exact recurrence rate of choledocholithiasis in the stone removal group remains unknown. However, we believe that the incidence 
of cholangitis is more important than the recurrence rate of stones in clinical practice. Therefore, this study is considered more relevant to actual clinical practice.

In conclusion, palliative EBS was effective in controlling cholangitis for a certain period of time among frail elderly patients with choledocholithiasis. However, a significantly higher number of patients required reintervention and re-hospitalization for cholangitis in the EBS group than in the complete stone removal group. The median duration of cholangitis-free periods in the palliative EBS group was significantly shorter than that in the complete stone removal group even after adjusting for background characteristics using PSM. Furthermore, one patient in the EBS group died due to severe cholangitis. Thus, palliative EBS should be indicated only in patients with choledocholithiasis who have a poor prognosis.

\section{Declarations}

\section{Conflicts of Interest}

The authors declare no conflicts of interest for this article.

\section{FUNDING}

There authors declare that no funding was received for this study.

\section{Ethics declarations}

This study was performed following the Helsinki Declaration of the World Medical Association. Written informed consent was obtained from all patients before ERCP. Informed consent for study enrollment was obtained in the form of an opt-out on the website. This study protocol was approved by Nara Medical University Ethics Committee (\#1360).

\section{Availability of data and materials}

The datasets used and/or analyzed during the current study are available from the corresponding author on reasonable request.

\section{Author contributions:}

Conceptualization: Koh Kitagawa

Data curation: Tadashi Namisaki

Formal analysis: Takemi Akahane, Norihisa Nishimura

Investigation: KK, Akira Mitoro, Masanori Furukawa

Methodology: KK, AM 
Project administration: KK, AM

Resources: KK, Takahiro Ozutsumi, Yukihisa Fujinaga, Yasuhiko Sawada

Supervision: Hitoshi Yoshiji

Writing-original draft: KK

Writing-review and editing: KK, AM

\section{References}

1. Paumgartner G, Sauerbruch T. SCIENCE \& PRACTICE Gallstones: pathogenesis. Lancet. 1991;338:1117-21.

2. Figueiredo JC, Haiman C, Porcel J, Buxbaum J, Stram D, Tambe N, et al. Sex and ethnic/racialspecific risk factors for gallbladder disease. BMC Gastroenterol. 2017;17:1-12.

3. Siegel JH, Kasmin FE. Biliary tract diseases in the elderly: Management and outcomes. Gut. 1997;41:433-5.

4. Buxbaum JL, Abbas Fehmi SM, Sultan S, Fishman DS, Qumseya BJ, Cortessis VK, et al. ASGE guideline on the role of endoscopy in the evaluation and management of choledocholithiasis. Gastrointest Endosc. 2019;89:1075-1105.

5. Yasuda I, Itoi T. Recent advances in endoscopic management of difficult bile duct stones. Dig Endosc. 2013;25:376-85.

6. McAlister VC, Davenport E, Renouf E. Cholecystectomy deferral in patients with endoscopic sphincterotomy. Cochrane Database Syst Rev. 2007.

7. Boerma D, Rauws EAJ, Keulemans YCA, Janssen IMC, Bolwerk CJM, Timmer R, et al. Wait-and-see policy or laparoscopic cholecystectomy after endoscopic sphincterotomy for bile-duct stones: A randomised trial. Lancet. 2002;360:761-5.

8. Wang CC, Tsai MC, Wang YT, Yang TW, Chen HY, Sung WW, et al. Role of Cholecystectomy in Choledocholithiasis Patients Underwent Endoscopic Retrograde Cholangiopancreatography. Sci Rep. 2019;9:1-7.

9. Sugiura R, Naruse $H$, Yamato $H$, Kudo T, Yamamoto $Y$, Hatanaka $K$, et al. Long-term outcomes and risk factors of recurrent biliary obstruction after permanent endoscopic biliary stenting for choledocholithiasis in high-risk patients. J Dig Dis. 2020;21:246-51.

10. Sbeit W, Khoury T, Kadah A, M. Livovsky D, Nubani A, Mari A, et al. Long-Term Safety of Endoscopic Biliary Stents for Cholangitis Complicating Choledocholithiasis: A Multi-Center Study. J Clin Med. 2020;9:2953.

11. Ang TL, Fock KM, Teo EK, Chua TS, Tan J. An audit of the outcome of long-term biliary stenting in the treatment of common bile duct stones in a general hospital. J Gastroenterol. 2006;41:765-71. 
12. Fan Z, Hawes R, Lawrence C, Zhang X, Zhang X, Lv W. Analysis of plastic stents in the treatment of large common bile duct stones in 45 patients. Dig Endosc. 2011;23:86-90.

13. Hong WD, Zhu QH, Huang QK. Endoscopic sphincterotomy plus endoprostheses in the treatment of large or multiple common bile duct stones. Dig Endosc. 2011;23:240-3.

14. Horiuchi A, Nakayama Y, Kajiyama M, Kato N, Kamijima T, Graham DY, et al. Biliary stenting in the management of large or multiple common bile duct stones. Gastrointest Endosc. 2010;71:12001203.e2. doi:10.1016/j.gie.2009.12.055.

15. Chan AC, Ng EK, Chung SC, Lai CW, Lau JY, Sung JJ, et al. Common bile duct stones become smaller after endoscopic biliary stenting. Endoscopy. 1998;30:356-9.

16. Bergman JJ, Rauws EA, Tijssen JG, Tytgat GNJ, Huibregtse K. Biliary endoprostheses in elderly patients with endoscopically irretrievable common bile duct stones: Report on 117 patients. Gastrointest Endosc. 1995;42:195-201.

17. Chopra KB, Peters RA, O'Toole PA, Williams SGJ, Gimson AES, Lombard MG, et al. Randomised study of endoscopic biliary endoprosthesis versus duct clearance for bileduct stones in high-risk patients. Lancet. 1996;348:791-3.

18. Kanda Y. Investigation of the freely available easy-to-use software "EZR" for medical statistics. Bone Marrow Transplant. 2013;48:452-8.

19. Kiriyama S, Kozaka K, Takada T, Strasberg SM, Pitt HA, Gabata T, et al. Tokyo Guidelines 2018: diagnostic criteria and severity grading of acute cholangitis (with videos). J Hepatobiliary Pancreat Sci. 2018;25:17-30.

20. Cotton PB, Eisen GM, Aabakken L, Baron TH, Hutter MM, Jacobson BC, et al. A lexicon for endoscopic adverse events: report of an ASGE workshop. Gastrointest Endosc. 2010;71:446-54.

21. Itoi T, Ryozawa S, Katanuma A, Okabe Y, Kato H, Horaguchi J, et al. Japan Gastroenterological Endoscopy Society guidelines for endoscopic papillary large balloon dilation. Dig Endosc. 2018;30:293-309.

22. Kim TH, Kim JH, Seo DW, Lee DK, Reddy ND, Rerknimitr R, et al. International consensus guidelines for endoscopic papillary large-balloon dilation. Gastrointest Endosc. 2016;83:37-47.

23. Ersoz G, Tekesin O, Ozutemiz AO, Gunsar F. Biliary sphincterotomy plus dilation with a large balloon for bile duct stones that are difficult to extract. Gastrointest Endosc. 2003;57:156-9.

24. Navaneethan U, Hasan MK, Kommaraju K, Zhu X, Hebert-Magee S, Hawes RH, et al. Digital, singleoperator cholangiopancreatoscopy in the diagnosis and management of pancreatobiliary disorders: a multicenter clinical experience (with video). Gastrointest Endosc. 2016;84:649-55.

25. Maydeo AP, Rerknimitr R, Lau JY, Aljebreen A, Niaz SK, Itoi T, et al. Cholangioscopy-guided lithotripsy for difficult bile duct stone clearance in a single session of ERCP: Results from a large multinational registry demonstrate high success rates. Endoscopy. 2019;51:922-9.

26. Shimatani M, Matsushita M, Takaoka M, Koyabu M, Ikeura T, Kato K, et al. Effective short doubleballoon enteroscope for diagnostic and therapeutic ERCP in patients with altered gastrointestinal anatomy: A large case series. Endoscopy. 2009;41:849-54. 
27. Yane K, Katanuma A, Maguchi H, Takahashi K, Kin T, Ikarashi S, et al. Short-type single-balloon enteroscope-assisted ERCP in postsurgical altered anatomy: Potential factors affecting procedural failure. Endoscopy. 2017;49:69-74.

28. Shimatani M, Takaoka M, Matsushita M, Okazaki K. Endoscopic approaches for pancreatobiliary diseases in patients with altered gastrointestinal anatomy. Dig Endosc. 2014;26 Suppl 1 August 2013:70-8.

29. Kaneko J, Kawata K, Watanabe S, Chida T, Matsushita M, Suda T, et al. Clinical characteristics and risk factors for stent-stone complex formation following biliary plastic stent placement in patients with common bile duct stones. J Hepatobiliary Pancreat Sci. 2018;25:448-54.

30. Di Giorgio P, Manes G, Grimaldi E, Schettino M, D’Alessandro A, Di Giorgio A, et al. Endoscopic plastic stenting for bile duct stones: Stent changing on demand or every 3 months. A prospective comparison study. Endoscopy. 2013;45:1014-7.

31. Yasui T, Takahata S, Kono H, Nagayoshi Y, Mori Y, Tsutsumi K, et al. Is cholecystectomy necessary after endoscopic treatment of bile duct stones in patients older than 80 years of age? $\mathrm{J}$ Gastroenterol. 2012;47:65-70.

\section{Tables}

Table 1 Baseline characteristics of the total and propensity-matched cohorts for palliative EBS and stone removal 


\begin{tabular}{|c|c|c|c|c|c|c|}
\hline & \multicolumn{3}{|c|}{ Total cohort } & \multicolumn{3}{|c|}{ Matched cohort } \\
\hline & $\begin{array}{l}\text { EBS } \\
(n= \\
25)\end{array}$ & $\begin{array}{l}\text { Complete } \\
\text { stone } \\
\text { removal } \\
(n=136)\end{array}$ & $\begin{array}{l}\mathrm{p} \\
\text { value }\end{array}$ & $\begin{array}{l}\text { EBS } \\
(n=25)\end{array}$ & $\begin{array}{l}\text { Complete } \\
\text { stone } \\
\text { removal } \\
(n=25)\end{array}$ & $\begin{array}{l}\mathrm{p} \\
\text { value }\end{array}$ \\
\hline Age, median (range), years & $\begin{array}{l}86.0 \\
(75- \\
95)\end{array}$ & $\begin{array}{l}81.0(75- \\
101)\end{array}$ & $\dot{0} 01$ & $\begin{array}{l}86.0 \\
(75-95)\end{array}$ & $\begin{array}{l}84.0(75- \\
87)\end{array}$ & 0.20 \\
\hline Sex, male/female & $14 / 11$ & $85 / 51$ & 0.66 & $14 / 11$ & $17 / 8$ & 0.56 \\
\hline $\begin{array}{l}\text { WHO performance status } \\
\text { score of } 3, n(\%)\end{array}$ & $2(8.0)$ & $9(6.6)$ & 0.68 & $2(8.0)$ & $2(8.0)$ & 1.00 \\
\hline $\begin{array}{l}\text { Antiplatelet or anticoagulant } \\
\text { therapy, } n(\%)\end{array}$ & $\begin{array}{l}10 \\
(40.0)\end{array}$ & $46(33.8)$ & 0.65 & $\begin{array}{l}10 \\
(40.0)\end{array}$ & $10(40.0)$ & 1.00 \\
\hline Cardiovascular disease, $n(\%)$ & $\begin{array}{l}9 \\
(36.0)\end{array}$ & $36(26.5)$ & 0.34 & $9(36.0)$ & $10(40.0)$ & 1.00 \\
\hline Dementia, $n(\%)$ & $\begin{array}{l}10 \\
(40.0)\end{array}$ & $16(11.8)$ & $\dot{0} 01$ & $\begin{array}{l}10 \\
(40.0)\end{array}$ & $8(32.0)$ & 0.77 \\
\hline $\begin{array}{l}\text { History of cerebral } \\
\text { infarction, } n(\%)\end{array}$ & $\begin{array}{l}6 \\
(24.0)\end{array}$ & $12(8.8)$ & 0.04 & $6(24.0)$ & $5(20.0)$ & 1.00 \\
\hline Malignant neoplasm, $n(\%)$ & $\begin{array}{l}6 \\
(24.0)\end{array}$ & $28(20.6)$ & 0.79 & $6(24.0)$ & $7(28.0)$ & 1.00 \\
\hline \multicolumn{7}{|l|}{ Gallstone, $n(\%)$} \\
\hline $\begin{array}{l}\text { Preserved gallbladder with } \\
\text { gallstones }\end{array}$ & $\begin{array}{l}14 \\
(56.0)\end{array}$ & $32(23.5)$ & $\dot{0.01}$ & $\begin{array}{l}14 \\
(56.0)\end{array}$ & $14(56.0)$ & 1.00 \\
\hline $\begin{array}{l}\text { Periampullary diverticulum, } n \\
\text { (\%) }\end{array}$ & $\begin{array}{l}13 \\
(52.0)\end{array}$ & $34(25.2)$ & 0.02 & $\begin{array}{l}13 \\
(52.0)\end{array}$ & $12(48.0)$ & 1.00 \\
\hline $\begin{array}{l}\text { Surgically-altered anatomyt, } \\
n(\%)\end{array}$ & $\begin{array}{l}7 \\
(28.0)\end{array}$ & $12(8.8)$ & 0.01 & $7(28.0)$ & $7(28.0)$ & 1.00 \\
\hline $\begin{array}{l}\text { Diameter of common bile } \\
\text { duct, median (range), mm }\end{array}$ & $\begin{array}{l}13.0 \\
(7-23)\end{array}$ & $11.0(4-28)$ & 0.04 & $\begin{array}{l}13.0(7- \\
23)\end{array}$ & $\begin{array}{l}13.0(6- \\
28)\end{array}$ & 0.98 \\
\hline $\begin{array}{l}\text { Diameter of stones, median } \\
\text { (range), } \mathrm{mm}\end{array}$ & $\begin{array}{l}10.0 \\
(4-18)\end{array}$ & $8.0(1-28)$ & 0.02 & $\begin{array}{l}10.0(4- \\
18)\end{array}$ & $\begin{array}{l}10.0(2- \\
28)\end{array}$ & 0.93 \\
\hline $\begin{array}{l}\text { Number of stones, median } \\
\text { (range) }\end{array}$ & $\begin{array}{l}2.0 \\
(1-10)\end{array}$ & $2.5(1-20)$ & 0.79 & $\begin{array}{l}2.0(1- \\
10)\end{array}$ & $3.0(1-10)$ & 0.75 \\
\hline
\end{tabular}

† Cases of Billroth-I reconstruction method were not included. 
Table 2 Endoscopic procedures and adverse events in the matched cohort

\begin{tabular}{|c|c|c|c|}
\hline & EBS & Complete stone removal & $\mathrm{p}$ value \\
\hline Total number of patients & $\mathrm{n}=25$ & $\mathrm{n}=25$ & \\
\hline \multicolumn{4}{|l|}{ Ampullary intervention } \\
\hline ES, $n(\%)$ & $2(8.0)$ & $18(72.0)$ & \\
\hline EPBD, $n(\%)$ & & $1(4.0)$ & \\
\hline EPLBD, $n(\%)$ & $1(4.0)$ & & \\
\hline EPLBD with ES, $n(\%)$ & & $6(24.0)$ & \\
\hline \multicolumn{4}{|l|}{ Type of stent } \\
\hline Straight type, $n(\%)$ & $17(68.0)$ & & \\
\hline Pig tail type, $n(\%)$ & $8(32.0)$ & & \\
\hline \multicolumn{4}{|l|}{ Length of stent } \\
\hline $5 \mathrm{~cm} / 7 \mathrm{~cm} / 9 \mathrm{~cm} / 10 \mathrm{~cm}, n$ & $9 / 13 / 2 / 1$ & & \\
\hline \multicolumn{4}{|l|}{ Diameter of stent } \\
\hline 7Fr/8.5Fr, $n$ & $22 / 3$ & & \\
\hline \multicolumn{4}{|c|}{ Total number of ERCP sessions } \\
\hline $1, n(\%)$ & $22(88.0)$ & $17(68.0)$ & 0.17 \\
\hline $2-3, n(\%)$ & $3(12.0)$ & $8(32.0)$ & \\
\hline Adverse eventst (AE), n (\%) & $4(16.0)$ & $2(8.0)$ & 0.67 \\
\hline
\end{tabular}

\section{Early AEs}

\begin{tabular}{lll}
\hline Acute pancreatitis (mild) & $1(4.0)$ & $2(8 \%)$ \\
\hline Aspiration pneumonia (mild) & $1(4.0)$ \\
\hline Retroperitoneal perforation (severe) & $1(4.0)$ \\
\hline Late AEs & \\
\hline Acute cholecystitis (moderate) & $1(4.0)$
\end{tabular}

ES, endoscopic sphincterotomy; EPBD, endoscopic papillary balloon dilatation; EPLBD, endoscopic large balloon dilatation

† Except for cholangitis or stent-related adverse events. 
Table 3 Cholangitis and mortality

\begin{tabular}{llll} 
& EBS & Complete stone removal & p value \\
\hline Total number of patients & $\mathrm{n}=25$ & $\mathrm{n}=25$ & \\
\hline Follow-up period, median (range), days & $456(8-1676)$ & $378(28-2364)$ & 0.88 \\
\hline Cholangitis, $n$ (\%) & $12(48.0)$ & $1(4.0)$ & \\
\hline Causes of cholangitis & & & \\
\hline Stent migration, $n$ (\%) & $7(28.0)$ & & \\
\hline Stent occlusiont, $n$ (\%) & $5(20.0)$ & & \\
\hline Recurrence of choledocholithiasis, $n$ (\%) & & $1(4.0)$ & \\
\hline Severity of cholangitis & & & \\
\hline Moderate, $n$ (\%) & $11(44.0)$ & $1(4.0)$ & \\
\hline Severe, $n$ (\%) & $1(4.0)$ & & \\
\hline Mortality, $n$ (\%) & $3(12.0)$ & $2(8.0)$ & \\
\hline Causes of mortality & & & \\
\hline Pneumonia & $1(4.0)$ & & \\
\hline Renal failure & $1(4.0)$ & & \\
\hline Severe cholangitis & $1(4.0)$ & & \\
\hline Gastric cancer & & & \\
\hline Length of hospital stay, median (range), days & $16(2-396)$ & & \\
\hline Including a patient with stent-stone complex formation. & & \\
\hline
\end{tabular}

\section{Figures}




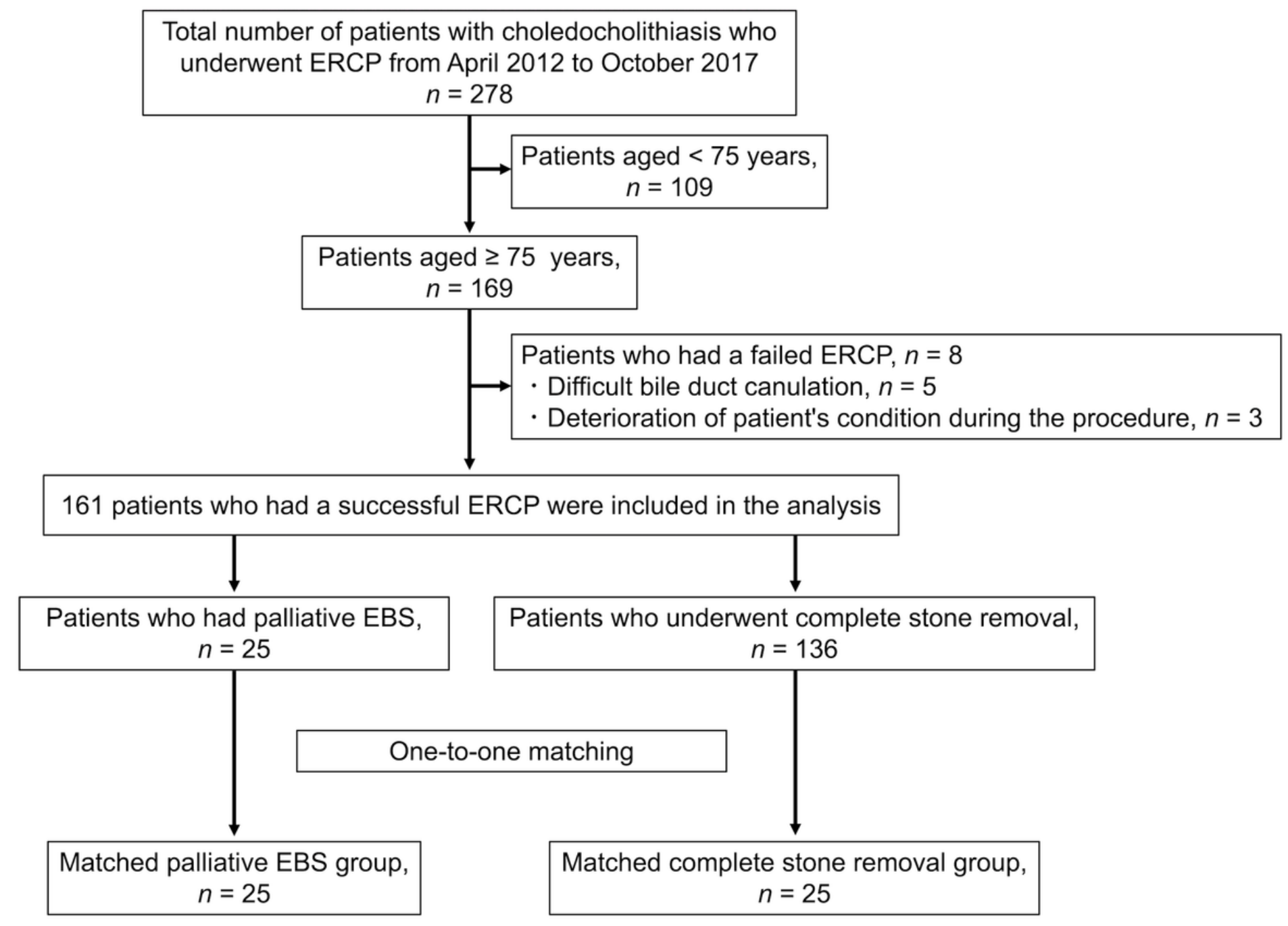

\section{Figure 1}

Flowchart of patient selection Flowchart of patient selection into matched palliative EBS and complete stone removal groups. (ERCP, endoscopic retrograde cholangiopancreatography; EBS, endoscopic biliary stenting). 


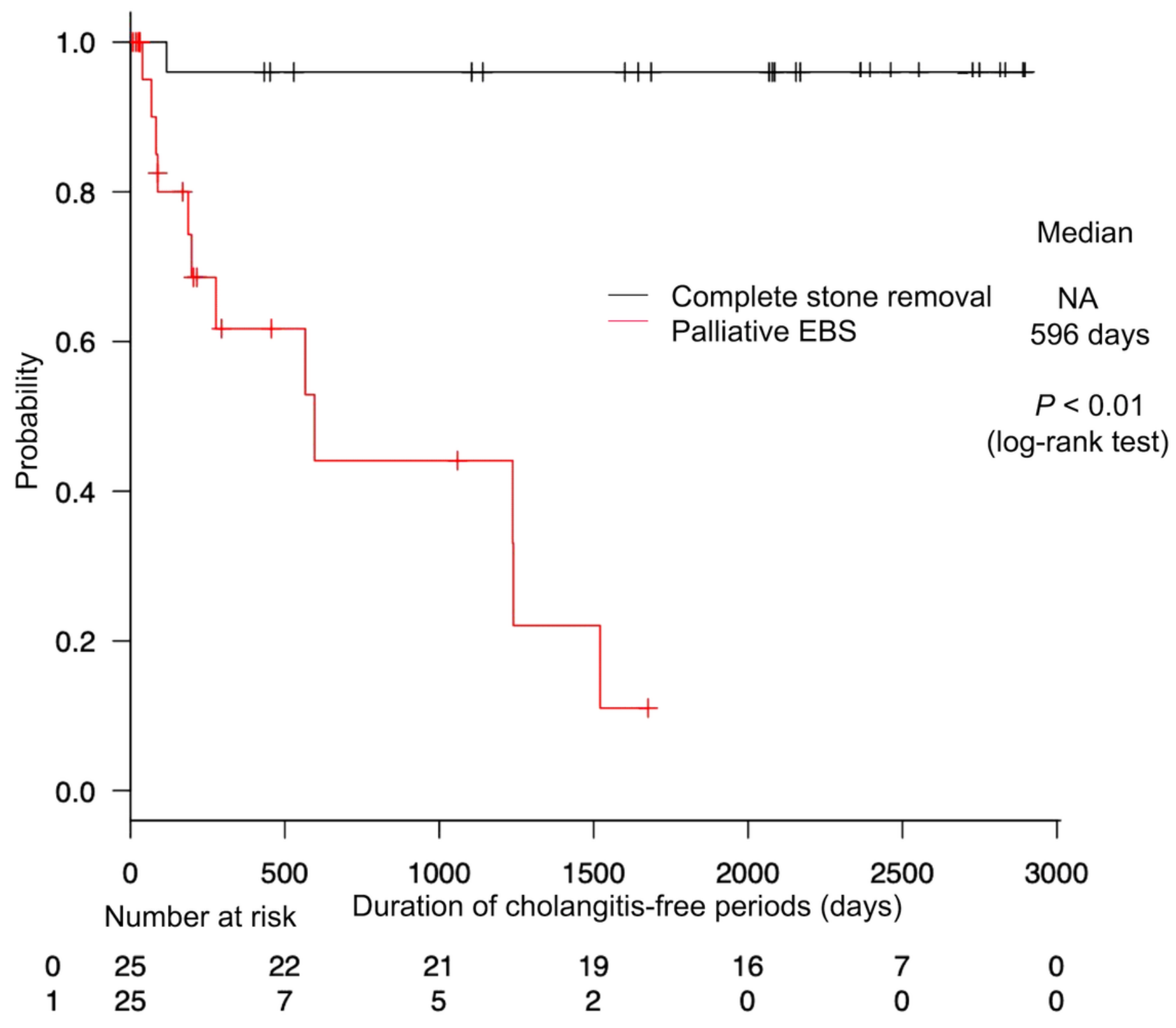

Figure 2

Duration of cholangitis-free periods Kaplan-Meier graph showing the duration of cholangitis-free periods. The duration of EBS was significantly shorter than that of complete stone removal $(p<0.01, \log$ rank test; EBS, endoscopic biliary stenting; NA, not applicable). 


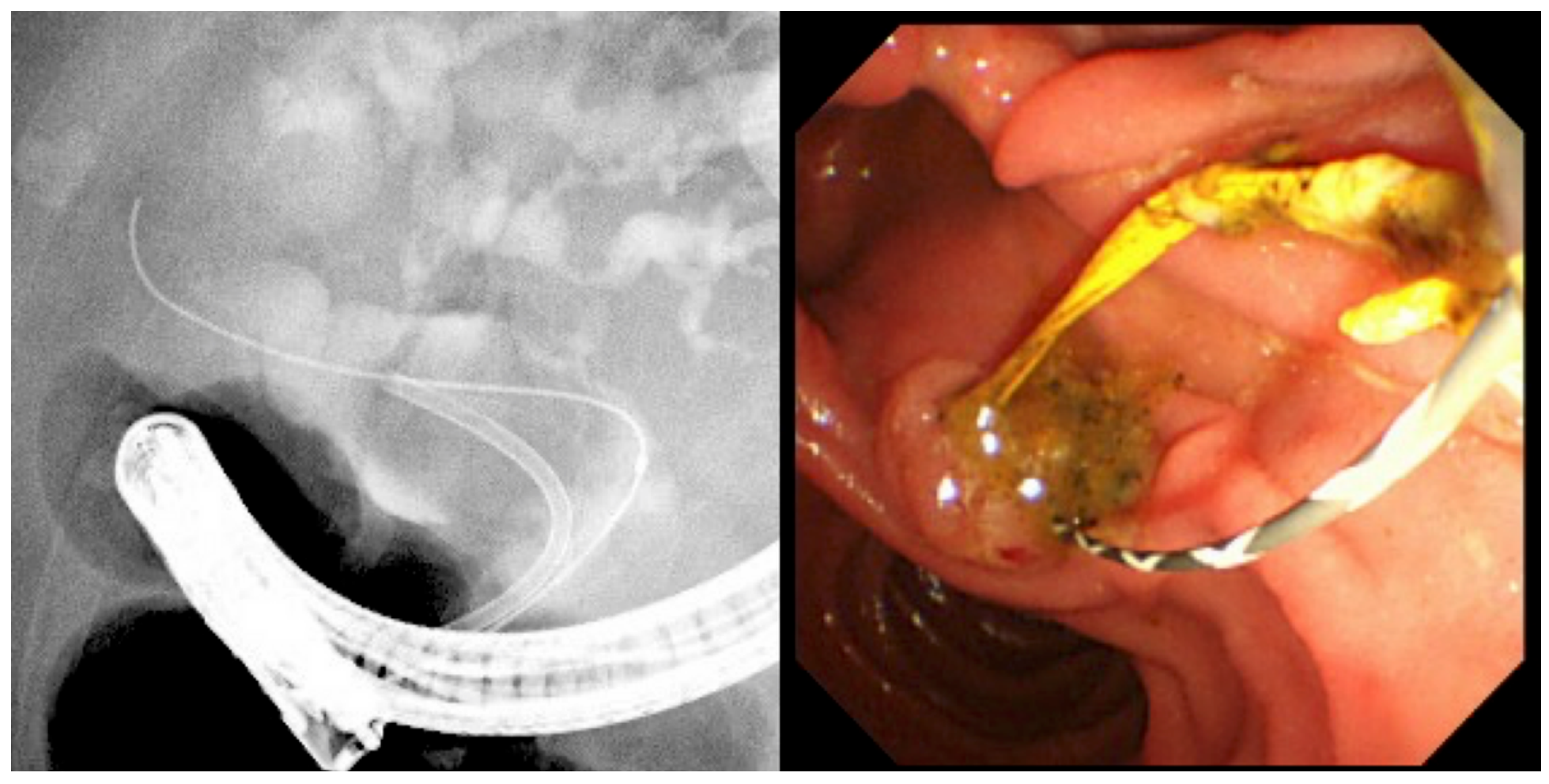

\section{Figure 3}

Stent-stone complex One patient in the palliative EBS group had stent-stone complex. He developed cholangitis 3 years after the initial ERCP stent placement. ERCP was performed again, and the stent ruptured upon removal (EBS, endoscopic biliary stenting; ERCP, endoscopic retrograde cholangiopancreatography). 